\title{
Measurement of informal care time in a study of patients with dementia
}

\author{
Simone Neubauer, ${ }^{1}$ Rolf Holle, ${ }^{1}$ Petra Menn, \\ Maria Grossfeld-Schmitz and Elmar Graesel ${ }^{2}$ \\ ${ }^{1}$ Helmholtz Zentrum München, Institute of Health Economics and Health Care Management, Neuherberg, \\ Germany \\ ${ }^{2}$ University Hospital Erlangen, Department of Psychiatry and Psychotherapy, Medical Psychology and Medical \\ Sociology, Erlangen, Germany
}

ABSTRACT

Background: Previous assessments of informal care time have tended to consider only the amount of time spent with the patient by the primary informal caregiver; however, in many cases, more than one person is providing care for the patient. We assess total informal care time of people caring for patients with dementia, and estimate the bias that can arise if consideration is not made of the time spent by all participating informal caregivers.

Method: We used an extended version of the questions on informal care time from the Resource Utilization in Dementia (RUD) instrument. Caregivers were asked to state the number of days and the number of hours on a typical day they had assisted the patient in activities of daily living (ADL), instrumental ADL (IADL), and supervision during the last four weeks. Multivariate regression analyses were conducted to identify factors that could account for the amount of informal care time.

Results: 357 informal caregivers took part. Values were missing from only $4.5 \%$ of all interviews. On average, the primary informal caregiver cared for the patient $1.5,2.1$ and 1.9 hours per day in ADL, IADL and supervision respectively. Fifty-seven percent of all patients had more than one informal caregiver. Total informal care time was underestimated by about $14 \%$ if the time of caregivers other than the primary caregiver was not taken into account. The informal care time was significantly higher if the caregiver was the patient's partner and the patient's health status was lower.

Conclusion: Our results show that most previous studies probably underestimated costs of informal care because the time of informal caregivers other than the primary caregiver was not considered.

Key words: dementia, informal care, RUD, measurement, economic evaluation

Correspondence should be addressed to: Simone Neubauer, Helmholtz Zentrum München, Institute of Health Economics and Health Care Management, Ingolstaedter Landstr. 1, 85764 Neuherberg, Germany. Phone: +49 (0) 893187 1240; Fax: +49 (0) 893187 3375. Email: simone.neubauer@helmholtz-muenchen.de. Received: 14 Feb 2008; revision requested 10 Apr 2008; revised version received 18 Apr 2008; accepted 21 Apr 2008. First published online 8 July 2008. 


\section{Introduction}

The continuing increase in life expectancy and the increasing incidence rate of dementia with age are likely to lead to a rise in the number of people with dementia. According to Ferri et al. (2005), about 24.3 million people have dementia worldwide, with 4.6 million new cases of dementia every year, and the prevalence of dementia is estimated to increase to 81.1 million people by 2040 .

Several international studies have evaluated non-medical interventions aimed at postponing institutional care. These interventions sought to improve the situation for patients with dementia living in private households, as well as that of their informal caregivers. These studies are frequently accompanied by economic evaluations (Mittelman et al., 1993; Droes et al., 2004; Jansen et al., 2005; Belle et al., 2006). In assessing the cost-effectiveness of such interventions from a societal perspective, informal care must be considered as a resource because it plays a substantial role in caring for patients with dementia living at home (Gold et al., 1996; Drummond et al., 2005; Wimo et al., 2006). Omission of costs of informal care would bias cost-effectiveness against formal care in favor of informal care (Gold et al., 1996).

Informal care time can be measured in different ways and various instruments have been developed to assess that time. Most apply the recall method, e.g. the Caregiver Activities Time Survey (CATS; Clipp and Moore, 1995), the Caregiver Activity Survey (CAS; Davis et al., 1997) and the Resource Utilization in Dementia (RUD) instrument (Wimo et al., 1998). All the instruments have been applied to caregivers of people with dementia. Van den Berg and Spauwen (2006) used the diary method (sometimes regarded as the gold standard) in a study of patients suffering from predominantly psychological, neurological and musculoskeletal diseases. All instruments assessed (parts of) activities of daily living (ADL), instrumental ADL (IADL) and supervision, with the exception of the diary method used by van den Berg and Spauwen (2006) which did not include supervision time.

To assess informal care time in our study, we decided to use the recall method as it is less time-consuming and less complex than the diary method. Of the three existing instruments applying the recall method, we chose to use the questions from RUD as these consider the widest range of care activities.

Until now, assessment of informal care time has been restricted to one caregiver - in most cases, the primary caregiver. However, patients with dementia often receive assistance from more than one informal caregiver (Engels et al., 2005). Therefore, we extended the RUD instrument to include assessments of the time given by other informal caregivers. In this paper, the acceptance and plausibility of this new version are reported. We also present our findings on informal care time and its influencing factors.

\section{Methods}

\section{Patient criteria and data collection}

Data were collected within the IDA study (IDA being the German abbreviation for "Dementia Care Initiative in Primary Practice.") The study region, Middle 
Franconia, is a mixed urban-rural area in south-east Germany. The main aim of this cluster-randomized study is to find out whether further training of general practitioners (GPs) and the offer of family counseling can delay nursing home placement of patients with dementia who are presently being cared for in the family home.

The inclusion criteria for the study were: the patients must have a Minimental State Examination (MMSE) score between 10 and 24 points, be aged over 65 years, receive support from a family caregiver and be living at home. People with a MMSE score below 10 were excluded since the intervention was not expected to be successful for this severely impaired patient group, where the time before a nursing home placement or the remaining life time might be too short. Patients with a nursing home placement planned in the shortterm or with a terminal prognosis within six months, and those unable to give written consent were excluded. The patients were divided into three groups: two non-medical interventions were compared with a control group with respect to specific outcome criteria. Control group A received regular treatment, whereas the two intervention groups $\mathrm{B}$ and $\mathrm{C}$ were recommended support groups and offered family counseling after the first follow-up (B) or beginning at baseline (C) by their GPs. The primary endpoint was the time the patient ceased to live at home.

Data were collected at baseline and at follow-up after 12 months and two years. GPs provided the patient data, and data were collected from family caregivers in computer-aided telephone interviews at the baseline and follow-ups.

Because we wanted to estimate the cost-effectiveness of the interventions from a societal perspective, the exact measurement of time spent in informal care was a primary point of our interest. Apart from the detailed assessment of informal care time, the interview also included the Barthel Index (Lubke et al., 2004), two subscales of the Nurses' Observation Scale for Geriatric Patients (NOSGER, subscales IADL and disturbing behavior; Wahle et al., 1996), and assessment of the use of formal care by home care services. Further follow-up interviews are planned to take place after one and two years, but are not yet completed. The interviewer had the option to attach notes to each question on general statements or comments by the respondent. If subjects did not want to conduct the interview by telephone, they could complete a written version of the questionnaire. If the written questionnaires were returned with values missing, we refrained from contacting these subjects again. In this paper, we present data from baseline interviews that were conducted between October 2005 and April 2007.

The study protocol was approved by the ethics committee of the Bavarian Chamber of Physicians and is registered as ISRCTN68329593 - Dementia Care Initiative in Primary Practice (German title: Initiative Demenzversorgung in der Allgemeinmedizin).

\section{Measurement of informal care time}

The RUD instrument assesses how many days during the last month and, on these days, how many hours on average the primary informal caregiver was 
providing services to the patient (Wimo et al., 1998). Informal care activities are divided into three categories: ADL, IADL and supervision. While ADL includes activities such as toilet visits, bathing and dressing, IADL comprises more complex activities such as shopping, food preparation and housekeeping. Wimo and Nordberg tested the validity and reliability of the RUD instrument. The validity was tested by correlating the observed informal care time with the estimated time. While the validity for IADL time measurement was poor, the validity was good for ADL and supervision. Test-retest reliability was good (Wimo and Nordberg, 2007).

At the start of the interview, the interviewer would ask each respondent whether he/she was the primary caregiver of the patient with dementia. We did not specify the question, but left the definition to the respondent. In some cases, it was not the primary caregiver who participated in the study and was interviewed about informal care time.

For all three activity categories (ADL, IADL and supervision), the caregiver was asked whether the patient needed help in the respective category. If the answer was yes, the interviewer then asked how much time was spent on these activities. They were asked to report on how many days they had assisted the patient during the last four weeks, and to state how many hours they had assisted the patient on these days on average. We tried to restrict the assessment of IADL time to the additional time required owing to the dementia only. For example, if the caregiver is the spouse and has always prepared the food for the partner who now has dementia, and the caregiver does not now need more time for this activity, then the additional time is zero. Supervision includes additional time not considered part of ADL and IADL time. If the patient was not at home during the previous four weeks (e.g. due to a hospital stay), the amount of informal care time before the patient's absence was assessed. If the respondent was the primary informal caregiver of two patients with dementia (e.g. a couple), we assessed the time for ADL separately for each patient. As most IADL and supervision activities are performed for both patients simultaneously, we assessed that time only once and split it between both patients equally.

We presumed that often more than one person would be involved in caring for the patient and that it would be essential to consider this when measuring the total amount of informal care time. Therefore, in contrast to the RUD instrument, we additionally asked the respondent to identify other family members, friends or neighbors who support the patient. If others were identified, the respondent would also report the time they spent providing assistance to the patient. These times were also assessed by the number of days during the previous four weeks and hours on a typical day, and the respondent was asked to report the sum of time of all other informal caregivers (Table 1).

\section{Statistical methods}

We analyzed the time the primary and other informal caregivers spent assisting the patient in order to assess the potential underestimation of total informal care time when only the time of one caregiver is considered, even if this is usually the primary caregiver. T-tests were used to analyze the significance of differences 
Table 1. Questions on informal care time.

\begin{tabular}{|c|c|c|c|c|}
\hline & \multicolumn{2}{|c|}{$\begin{array}{l}\text { INTERVIEWED } \\
\text { INFORMAL } \\
\text { CAREGIVER }\end{array}$} & \multicolumn{2}{|c|}{$\begin{array}{c}\text { OTHER } \\
(\text { NON-INTERVIEWED }) \\
\text { INFORMAL } \\
\text { CAREGIVERS }\end{array}$} \\
\hline LAST FOUR WEEKS & $\begin{array}{l}\text { ON HOW } \\
\text { MANY } \\
\text { DAYS }\end{array}$ & $\begin{array}{l}\text { ON THESE } \\
\text { DAYS, } \\
\text { HOW } \\
\text { MANY } \\
\text { HOURS? }\end{array}$ & $\begin{array}{l}\text { ON H OW } \\
\text { MANY } \\
\text { DAYS }\end{array}$ & $\begin{array}{l}\text { ON THESE } \\
\text { DAYS, } \\
\text { HOW } \\
\text { MANY } \\
\text { HOURS? }\end{array}$ \\
\hline $\begin{array}{l}\text { ADL (toilet visits, eating, } \\
\text { dressing, grooming, } \\
\text { walking, bathing) } \\
\text { IADL (shopping, food } \\
\text { preparation, housekeeping, } \\
\text { laundry, transportation, } \\
\text { taking medication, } \\
\text { managing financial } \\
\text { matters) } \\
\text { Supervision (preventing } \\
\text { dangerous events) }\end{array}$ & & & & \\
\hline
\end{tabular}

in total informal care time by respondent (primary vs. non-primary caregiver). Applying multivariate generalized linear regression models with beta-distribution and logit link, we examined factors influencing informal care time, such as sex, age, the type of relationship between patient and caregiver, health status and the use of formal services (Smithson and Verkuilen, 2006). Local regressions applying the SAS procedure PROC LOESS were performed to analyze the relationship between hours per day of the primary informal caregiver and the Barthel Index, according to the relationship between patient and caregiver. We used SAS 9.1 (SAS Institute Inc., Cary, NC, USA) to analyze the data.

\section{Results}

\section{Study population}

A total of 390 patients and their informal caregivers took part in the IDA study. Thirty-three informal caregivers did not want to participate in the interview or were not available despite several contact attempts. In sum, 357 informal caregivers were interviewed. In 26 cases, the respondent was not the primary informal caregiver of the patient. In five cases, the respondent was the primary caregiver for two patients with dementia. Table 2 gives an overview of the main descriptive statistics of the patients and their informal caregivers.

The mean age of the informal caregivers was 59 years and the majority were female. Patients were 80 years old on average and $68 \%$ of them were female. About one-third of the respondents cared for their partner, and more than half 
Table 2. Characteristics of patients and their informal caregivers

\begin{tabular}{|c|c|c|c|}
\hline C H A R A C TERISTICS & $\begin{array}{l}\text { MEAN/ } \\
\text { PERCENTAGE }\end{array}$ & ( S D ) & {$[\mathrm{MIN} ; \mathrm{MAX}]$} \\
\hline Age informal caregiver & 59.4 & (13.4) & {$[21 ; 89]$} \\
\hline Proportion of female informal caregivers & $73.3 \%$ & & \\
\hline Age patient & 80.2 & (6.7) & {$[65 ; 100]$} \\
\hline Proportion of female patients & $67.5 \%$ & & \\
\hline MMSE of the patient ${ }^{\mathrm{a}}$ & 18.6 & $(3.8)$ & {$[10 ; 24]$} \\
\hline Barthel Index of the patient $\mathrm{t}^{\mathrm{a}}$ & 72.9 & $(26.5)$ & {$[5 ; 100]$} \\
\hline NOSGER subscale IADL ${ }^{\mathrm{b}}$ & 15.9 & $(5.3)$ & {$[5 ; 25]$} \\
\hline NOSGER subscale disturbing behavior ${ }^{\mathrm{b}}$ & 9.5 & (3.5) & {$[5 ; 21]$} \\
\hline \multicolumn{4}{|l|}{$\begin{array}{l}\text { Social relationship between caregiver } \\
\text { and patient }\end{array}$} \\
\hline Partner & $32.2 \%$ & & \\
\hline Parent (-in-law) & $59.1 \%$ & & \\
\hline Other & $8.7 \%$ & & \\
\hline $\begin{array}{l}\text { Proprotion of patients and caregivers } \\
\text { living in the same household }\end{array}$ & $68.8 \%$ & & \\
\hline \multicolumn{4}{|l|}{ Education of the informal caregiver } \\
\hline Primary education & $67.6 \%$ & & \\
\hline Secondary education & $24.0 \%$ & & \\
\hline Tertiary education & $8.4 \%$ & & \\
\hline
\end{tabular}

${ }^{a}$ Higher scores indicate better cognitive functioning or better abilities of the patient (score range MMSE: 10-24, Barthel Index: 0-100).

${ }^{\mathrm{b}}$ Lower scores (score range 5-25) indicate better abilities of the patient.

MMSE = Mini-mental State Examination; NOSGER = Nurses' Observation Scale for Geriatric Patients; IADL $=$ instrumental activities of daily living.

for their parents/parents-in-law. Sixty-nine per cent of the caregivers lived in the same household as the patient.

\section{Feasibility, missing values and extreme values}

In all, 313 respondents answered the questions by telephone, whereas 44 informal caregivers $(12 \%)$ preferred to use the print version of the questionnaire. Only 16 interviews were incomplete in the informal care time section (4.5\%), with $49 \%$ of all missing values originating in the mail questionnaires. Respondents who were not the primary informal caregiver did not have more missing values than those who stated they were the primary informal caregivers. Most missing values (58\%) appeared in questions that concerned the time other caregivers spent on caring for the patient.

In general, caregivers were willing to give detailed information. Electronic notes made by the interviewer often specified the kind of activities patients needed help with, or included the minutes the informal caregiver needed for each of the stated activities (e.g. food preparation, toileting and medication). Some respondents said the patient needed assistance all day long. Furthermore, some interviewers documented that it was difficult for the caregiver to estimate 
Table 3. Time of the primary informal caregiver by ADL, IADL and supervision $(n=331)$

\begin{tabular}{|c|c|c|c|}
\hline PRIMARY INFORMAL CAREGIVER & A D L & I A D L & SUPERVISION \\
\hline$\%$ assist the patient each day & $47.0 \%$ & $64.6 \%$ & $30.6 \%$ \\
\hline$\%$ assist the patient some days per week & $19.7 \%$ & $28.1 \%$ & $7.9 \%$ \\
\hline$\%$ do not assist the patient at all & $33.3 \%$ & $7.3 \%$ & $61.5 \%$ \\
\hline Days during the last 4 weeks, mean (SD) & $15.2(13.0)$ & $20.9(10.5)$ & $9.5(12.9)$ \\
\hline Hours during the last 4 weeks, mean (SD) & $42.8(54.4)$ & $57.8(54.2)$ & $52.5(98.5)$ \\
\hline $\begin{array}{l}\text { Number of hours per day (over period of } 4 \\
\text { weeks), mean (SD) }\end{array}$ & $1.5(1.9)$ & $2.1(1.9)$ & $1.9(3.5)$ \\
\hline
\end{tabular}

the time spent providing care when patients and caregiver were living in the same household.

To check the plausibility of the stated time values, we assumed that the interviewed caregiver needed a minimum of six hours sleep per night resulting in a maximum care time of 18 hours per day. Interruptions of the caregiver's sleep at night by the patient were documented, but not counted as care time. Twentysix informal caregivers $(8 \%)$ stated that they assisted the patient more than 18 hours per day; all were living in the same household as the patient and assisted the patient each day. Furthermore, most of the 26 caregivers stated that at least 16 hours per day were spent on supervising alone. If persons stated more than 18 hours in sum, we assumed a misunderstanding of the question on additional time spent supervising the patient. In these cases, we shortened the time of supervision in order that the total amount of ADL, IADL and supervision per day totaled 18 hours.

Overall, the telephone interviews on informal care activities yielded complete and plausible answers from $93 \%$ of caregiver interviews, and the average time required for this part of the interview was four minutes (range: 1-12 minutes).

\section{Informal care time}

In the first instance we restricted our analysis to interviews with the primary informal caregiver $(\mathrm{n}=331)$. Forty-seven percent of the caregivers assisted the patient with ADL each day, while $33 \%$ did not provide any assistance with ADL (Table 3). On average, the primary informal caregiver assisted the patient on 15.2 days with ADL, on average for 1.5 hours per day. However, the distribution is skewed to the right (see Figure 1). Most informal caregivers (66\%) did not spend more than two hours per day assisting the patient with ADL. The respective figures for IADL and supervision are shown in Table 3.

In our study, $57 \%$ of the primary informal caregivers stated that there were additional people caring for the patient in one of the three categories under examination. Most of these other informal caregivers supported the patient in IADL ( $45 \%)$. About $10 \%$ of the primary informal caregivers even said that others assisted the patient in IADL every day (see Table 4). Twenty-nine per 


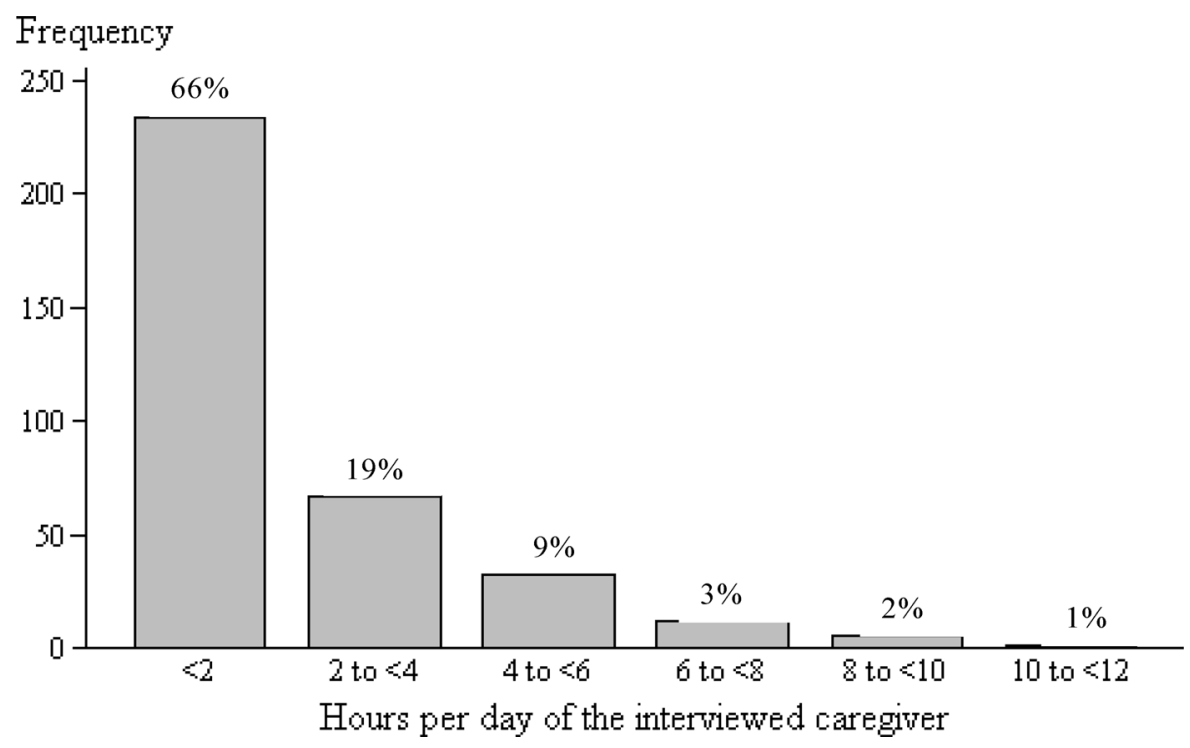

Figure 1. Distribution of hours per day in ADL of the interviewed caregivers.

Table 4. Time of other informal caregivers by ADL, IADL and supervision $(n=331)$

\begin{tabular}{|c|c|c|c|}
\hline & A D L & I A D L & SUPERVISION \\
\hline $\begin{array}{l}\% \text { of patients who get daily assistance of } \\
\text { others than the primary IC }\end{array}$ & $6.8 \%$ & $9.8 \%$ & $7.3 \%$ \\
\hline $\begin{array}{l}\% \text { of patients who get assistance of others } \\
\text { than the primary IC some days per week }\end{array}$ & $22.0 \%$ & $35.6 \%$ & $10.1 \%$ \\
\hline $\begin{array}{l}\% \text { of patients who do not get assistance of } \\
\text { other IC }\end{array}$ & $71.2 \%$ & $54.6 \%$ & $82.6 \%$ \\
\hline $\begin{array}{l}\text { Days of other IC during the last } 4 \text { weeks, } \\
\text { mean (SD) }\end{array}$ & $3.6(7.7)$ & $5.4(8.8)$ & $2.7(7.5)$ \\
\hline $\begin{array}{l}\text { Hours of other IC during the last } 4 \text { weeks, } \\
\text { mean (SD) }\end{array}$ & $6.3(16.0)$ & $9.2(17.8)$ & $9.6(41.0)$ \\
\hline $\begin{array}{l}\text { Average number of hours per day of other } \\
\text { IC (over a period of } 4 \text { weeks), mean (SD) }\end{array}$ & $0.2(0.6)$ & $0.3(0.6)$ & $0.3(1.5)$ \\
\hline
\end{tabular}

IC $=$ informal caregivers.

cent and $17 \%$ of the primary informal caregivers, respectively, stated that the patient also received assistance from others for $\mathrm{ADL}$ and supervision activities.

Other instruments assessing informal care time often do not include time spent by other caregivers, and, therefore, are likely to underestimate the total amount of informal care given to the patient. Because our data include the measurement of time spent both by the primary caregiver as well as by other caregivers, we were able to estimate the bias that would arise if only the time of the primary caregiver was assessed. Figure 2 (left-hand bars) shows the average 
Average hours per day

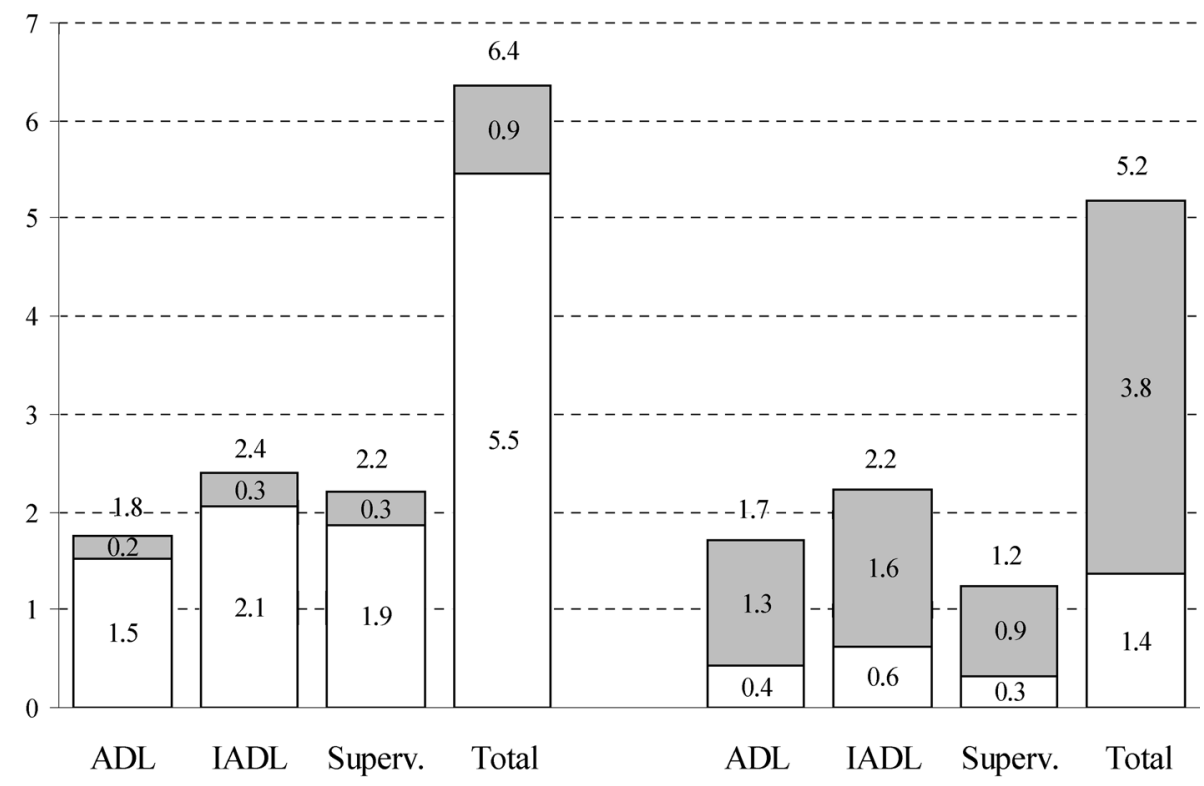

Respondent: Primary caregiver $(n=331)$

$\square$ Interviewed primary caregiver
$\square$ Others

Non-primary caregiver

$\square$ Interviewed non-primary caregiver

$\square$ Others (incl. primary caregiver)

Figure 2. Average hours per day spent on caring for the patient by activity, informal caregiver and respondent.

hours per day the interviewed primary informal caregiver and others spent on $\mathrm{ADL}$, IADL and supervision. It illustrates that informal care times would be underestimated by $13 \%$ (ADL), $14 \%$ (IADL) and 16\% (supervision), if only the times of the primary caregiver were considered. Overall, about $14 \%$ of the total time spent on informal care would be missed.

In 26 cases, the respondent was not the primary informal caregiver. In these cases, the time of the primary informal caregiver is included in the time others spent on caring for the patient, as reported by the interviewee (non-primary) caregiver (see Figure 2, right-hand bars). If we had not asked about the care time of others (including the time of the primary caregiver), and had only assessed the time of the respondent, we would have neglected about $77 \%$ of total time spent on informal care.

We compared total informal care time by respondent (primary caregiver vs. non-primary caregiver). None of the differences in the responses regarding care time (total and per category) were significant at the 5\% level. However, the lack of significance might be a result of the small sample size in the subgroup of non-primary caregivers $(n=26)$. The mean total time spent with the patient was 1.2 hours per day lower if the non-primary caregivers were interviewed (see Figure 2). The discrepancy can be explained mainly by the difference in total supervision time -1.1 hours. However, based on data from the patients' GPs, 
Table 5. Results of the beta regression

\begin{tabular}{|c|c|c|c|c|}
\hline \multirow[b]{2}{*}{ PARAMETER } & \multicolumn{2}{|c|}{$\begin{array}{l}\text { (A) TOTAL TIME OF } \\
\text { INTERVIEWED } \\
\text { CAREGIVER, N=335 }\end{array}$} & \multicolumn{2}{|c|}{$\begin{array}{c}\text { (B) TOTAL TIME OF } \\
\text { ALL CAREGIVERS, } \\
\text { N=329 }\end{array}$} \\
\hline & E S T I M ATE & P-VALUE & E S T I M ATE & P-VALUE \\
\hline Intercept & -2.40 & 0.024 & -3.66 & $<0.001$ \\
\hline Sex caregiver ${ }^{\mathrm{a}}$ & -0.25 & 0.110 & -0.09 & 0.421 \\
\hline Sex patient ${ }^{\mathrm{a}}$ & -0.09 & 0.603 & -0.06 & 0.647 \\
\hline Age caregiver & 0.01 & 0.289 & 0.01 & 0.165 \\
\hline Age patient & 0.01 & 0.555 & 0.00 & 0.627 \\
\hline $\begin{array}{l}\text { Relationship } \\
\text { patient/caregiver }\end{array}$ & 0.62 & 0.029 & 0.23 & 0.261 \\
\hline $\mathrm{MMSE}^{\mathrm{c}}$ & -0.01 & 0.586 & 0.00 & 0.937 \\
\hline Barthel-Index ${ }^{\mathrm{c}}$ & -0.02 & $<0.001$ & -0.01 & $<0.001$ \\
\hline NOSGER IADL ${ }^{\mathrm{d}}$ & 0.09 & $<0.001$ & 0.10 & $<0.001$ \\
\hline NOSGER behavior ${ }^{\mathrm{d}}$ & 0.09 & $<0.001$ & 0.07 & $<0.001$ \\
\hline Formal care $^{\mathrm{e}}$ & -0.35 & 0.015 & -0.34 & 0.003 \\
\hline Other caregivers ${ }^{\mathrm{e}}$ & -0.06 & 0.806 & 0.30 & 0.005 \\
\hline
\end{tabular}

${ }^{\mathrm{a}} 1=$ male, $0=$ female; ${ }^{\mathrm{b}} 1=$ partner, $0=$ other, ${ }^{\mathrm{c}}$ Higher scores indicate better cognitive functioning or better abilities of the patient (score range MMSE: 10-24, Barthel Index: 0-100); ${ }^{\mathrm{d}}$ Lower scores (score range 5-25) indicate better abilities of the patient; ${ }^{\mathrm{e}} 1=$ yes, $0=$ no.

MMSE = Mini-mental State Examination; NOSGER = Nurses' Observation Scale for Geriatric Patients; IADL $=$ instrumental activities of daily living.

where a non-primary caregiver was interviewed their patients did not have more severe that could explain a higher supervision time (e.g. likelihood of running away or aggressiveness). Total ADL time and total IADL time were only slightly higher for the primary caregivers.

\section{Factors related to informal care time}

We conducted multivariate regressions to analyze factors related to the amount of informal care time (Table 5). In regression (a), the dependent variable is the time spent by the interviewed informal caregiver assisting the patient per day, while in regression (b), it is the time spent by all informal caregivers.

Independent variables are the caregivers' and patients' sex and age, the relationship to the patient, Barthel Index, MMSE, NOSGER subscales for IADL and behavior, use of formal care and the assistance of further informal caregivers.

In regression (a), the sex, age, MMSE and availability of other informal caregivers had no significant impact on informal care time of the primary informal caregiver. However, informal care time was significantly lower if formal care was also provided. Furthermore, the Barthel Index, as well as the NOSGER subscales, had a significant impact: patients who could arrange ADL by themselves according to the Barthel Index needed less informal care time; patients with restricted abilities in IADL and behavior according to the NOSGER subscales needed more time for assistance. As the correlation between 
Hours per day of primary informal caregiver

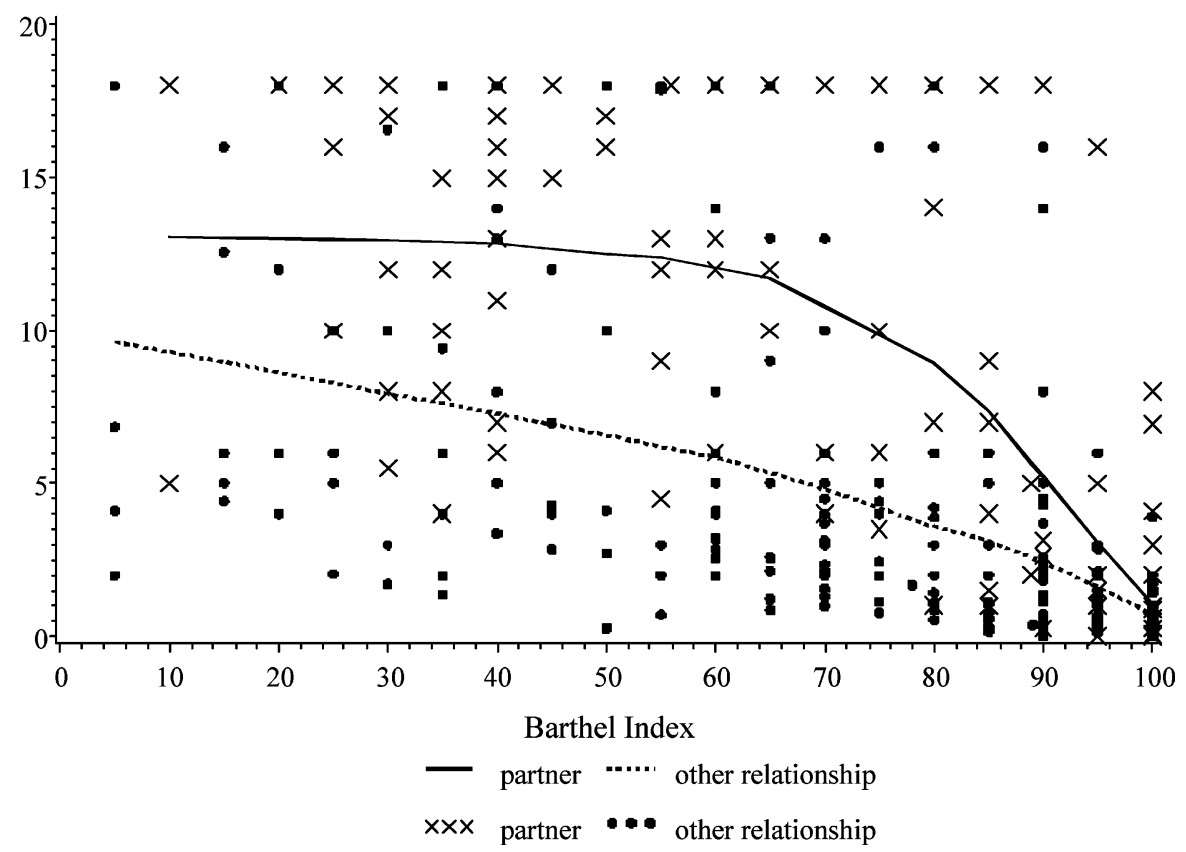

Figure 3. Local regression of hours per day of the primary informal caregiver on Barthel Index by relationship to the patient $(n=338)$.

the Barthel Index and the MMSE is significant, we additionally performed the regression without MMSE as the independent variable. However, results did not change (not shown). We additionally conducted regression analysis including only those respondents who were the primary informal caregiver of the patient. Parameters, as well as significance, did not change substantially (results not shown).

Regression (b) shows factors determining the total informal care time of all involved caregivers (primary and others). The variables "other caregivers" and "relationship to the patient," while not being statistically significant in regression (a) (and the former has the opposite sign), are statistically significant in regression (b). For the other independent variables, results differed only slightly.

The results did not change when we used only the ADL time (of interviewed caregiver or all caregivers) as the dependent variable. We also performed a regression analysis with the MMSE as the only independent variable and hours of informal care of the interviewed caregiver and all informal caregivers as the dependent variable, respectively. In both cases, the regression coefficient was statistically significant $(\mathrm{p}<0.001)$.

We analyzed the factor "relationship to the patient," which was statistically significant in regression (a), where the dependent variable is the time spent by the interviewed (usually primary) caregiver. The regression showed that the informal care time of the interviewed caregivers was higher when they were the 
partner of the patient. However, in nearly all cases the caregiver and patient live in the same household, which might explain why the caregiver assisted the patient more than other interviewed caregivers not living in the same household as the patient. Note that, even if only those primary caregivers who lived in the same household as the patient were considered, partners spent significantly more time than otherwise-related interviewed caregivers. While partners assisted the patient for 7.8 hours per day, other related people assisted for 5.7 hours per day. Local regression showed that, for the patients with lower ADL dependency (Barthel Index 95 to 100), all caregivers reported a small amount of informal care time, but with increasing ADL dependency (Barthel Index 60 to 95), the increase in informal care time was stronger in caregivers who were the patient's partner (see Figure 3). For a Barthel Index of approximately 60 and below, the amount of informal care time spent by the partner did not increase significantly with the patients' abilities.

\section{Discussion}

In this study we used an extended version of the questions on informal care time included in the RUD instrument, in order to incorporate the care time of those other than the interviewed informal caregiver. Most previous instruments assessed only the time spent by the primary informal caregiver, even though patients with dementia often receive assistance from two or more carers. Economic evaluations must crucially take into account the total time spent on informal care, irrespective of whether the informal care is provided by one or more people. Our study shows that the adapted version of the questionnaire is feasible. Furthermore, the findings demonstrate that considering the time of others increases the estimated total care time by more than $10 \%$.

Regardless of whether the primary or non-primary informal caregiver is interviewed, it is crucial to assess the time spent caring by both the respondent and any other caregivers. However, our results show that the primary informal caregiver provides a higher amount of total informal care time than any nonprimary informal caregivers. While the total ADL and IADL time did not differ between the two subgroups, total supervision time reported by non-primary caregivers was almost half the time reported by the primary caregivers. Nonprimary caregivers seem to be able to give valid answers on ADL and IADL time, but seem to underestimate supervision time (of other caregivers). As the non-primary caregiver spends less time with the patient, it is likely that the nonprimary caregiver underestimates the time others spend caring for the patient, especially the supervision time. Hence, even when assessing the time spent by all participating informal caregivers, it is advisable to interview the primary informal caregiver.

The time assessment would have been more reliable if the time of other informal caregivers had been estimated by themselves and not by the interviewed person. As mentioned before, it is likely that the proxy underestimated the informal care time of others. However, assessing the time of all involved caregivers personally would have been too time-consuming and costly. 
We decided not to develop a completely new instrument to assess informal care time but instead to modify one of the existing instruments as they provide a good basis for further refinements. Several instruments were available, such as the CATS (Clipp and Moore, 1995), CAS (Davis et al., 1997) and RUD (Wimo et al., 1998) instruments. We chose the RUD instrument for the following reasons: CATS does not assess systematically all activities that can be part of informal care and CAS also asks only for selected activities (Clipp and Moore, 1995; Davis et al., 1997). For example, while CATS does not include walking, cooking and shopping, CAS does not consider bathing, toilet visits and housekeeping. In contrast, the RUD instrument systematically considers a wide range of activities of ADL, IADL and supervision.

Estimating the exact care time during a past period of time is difficult. Wimo and Nordberg (2007) analyzed the correlation between observed and estimated caregiving time for the previous month. They concluded that correlations are good for ADL and supervision, while they are low for IADL. Assisting the patient in ADL can more easily be identified as informal care time, compared with IADL or supervision. As a healthy person is able to perform ADL, assistance provided to another person in this area can be characterized as informal care. In contrast, even if a person is completely healthy, other people may perform IADL for them such as cooking or cleaning. However, in this situation the other people are not performing "informal care". Distinguishing between "normal" activities and "informal care" activities remains a challenge for further research.

We did not apply the diary method used by van den Berg and Spauwen (2006) for four main reasons: first, the recall method is less time- and costintensive. Second, van den Berg and Spauwen reported a non-response rate of $11 \%$. Most of the non-responders found the diary method too difficult to follow. Presumably, the non-response rate would have been even higher in our study as $25 \%$ of the caregivers in our study population were aged between 70 and 89 years. Third, the diary did not include the time the informal caregiver supervised the patient. However, with increasing levels of dementia, the time the informal caregiver spends on supervision gets more extensive. While patients with mild dementia (MMSE 18-24) were supervised 1.7 hours per day, those with moderate dementia (MMSE 10-17) were supervised 2.9 hours per day. This amount could decrease in patients with severe dementia where they are less mobile. Fourth, the adjustment of joint production as performed by van den Berg and Spauwen could lead to a substantial bias in time measurement, as this does not distinguish between activities that were conducted simultaneously and consecutively.

The higher number of hours spent on assisting the patient with IADL compared with ADL can be explained by the fact that IADL are more complex than ADL. Furthermore, as our study population only includes patients with mild to moderate dementia, there are more patients who need no assistance in ADL compared with studies that also included patients with severe patients. Another factor is that IADL, such as food preparation or cleaning, are often not only performed for the patient but also for the primary informal caregivers themselves. Estimating the time spent additionally for the patient is difficult; it is possible that the caregivers state the full amount of time spent on the 
activities, instead of the additional time required as part of caring specifically for the patient. Van den Berg and colleagues compared the time allocation of the caregivers with that of the general public with respect to household activities of daily living (HDL). The total amount of HDL of the caregivers was higher than that of the general public (van den Berg et al., 2005c).

We did not consider caregivers' sleeping time as supervision and implicitly assumed that caregivers do not supervise during sleep. However, about $15 \%$ of the primary informal caregivers stated that they interrupt their night sleep in order to care for the patient every night. Another $21 \%$ had interrupted their night sleep at least once over the four-week period. Hence, there is a trend to underestimate supervision time. Some of this assistance at night could be included in ADL time, e.g. if the patient needs to go to the toilet.

Several studies have assessed the time spent on providing formal and informal services for patients with dementia. Hours per day ranged between 8 and 17.2 if ADL, IADL and supervision were covered (Clipp and Moore, 1995; Davis et al., 1997; O'Shea and O'Reilly, 2000; Wimo et al., 2000). The lowest number of hours was reported by a study on patients suffering from mild to moderate dementia. The other studies did not specify the levels of dementia considered, or included patients with severe dementia. In our study, with patients suffering from mild to moderate dementia, average informal care time of the interviewed caregiver is 5.2 hours per day. Sixty-five per cent of the recruited patients have mild dementia, which could explain the relatively low amount of informal care time as hours vary significantly with the degree of dementia. Several studies have shown that informal care time increases with the loss of cognitive functioning. Supervision time in particular plays an important role when caring for people with severe dementia (Jonsson et al., 2006). Another explanation is that we tried to assess only the additional time in IADL. Other studies have not explicitly assessed the additional time, but instead assessed the full amount of IADL time (Clipp and Moore, 1995; Davis et al., 1997; O'Shea and O'Reilly, 2000; Wimo et al., 2000). Furthermore, other studies did not restrict daily informal care time to 18 hours per day (Clipp and Moore, 1995; Davis et al., 1997). Davis and colleagues (1997) reported a maximum of 75 hours per day as the "caregivers were asked to record the time spent engaging simultaneously in different activities if the activities were contemporaneous" (Davis et al., 1997).

The variable "other caregivers" is only significant in regression (b), where the total informal care time of all involved caregivers (primary and others) is the dependent variable. The change could be explained as follows: in regression (a) (time of primary informal caregiver as the dependent variable), this variable shows a possible substitution effect. If the primary informal caregivers get assistance from other persons, they are relieved of care. As regression (b) has the total time of all caregivers as the dependent variable, the variable "other caregivers" might reflect the fact that total informal care time is higher if more persons are involved in caring for the patient.

We focused our analysis on the assessment of informal care time. Several papers on the application of different methods of valuing informal care time have been published recently (van den Berg et al., 2005a; 2005b; 2005c). Van 
den Berg and colleagues provide a good review on valuation methods of informal care (van den Berg et al., 2004).

We did not consider possible positive effects from caring for a loved one. Brouwer and colleagues show that informal caregivers derive utility from the process of providing care (Brouwer et al., 2005; 2006). In their studies, about half of the caregivers would be less happy if someone else took over their care tasks. This aspect should be included in economic evaluations. Brouwer and colleagues proposed to include this process utility in terms of quality of life of the caregiver (Brouwer et al., 1999).

Our results show that costs of informal care have previously been underestimated as the time spent by informal caregivers additional to the primary caregiver has not been considered. If informal care is assessed in the context of, for example, cost-effectiveness analysis, the total amount of informal care time must be considered.

\section{Conflict of interest declaration}

The sponsors have commissioned two academic research institutes to undertake scientific evaluation of the IDA project by giving unconditional research funds. A contract between the sponsors and academic researchers ensures that the latter have full scientific responsibility and the right to publish the results. Members (and former member S. Ruckdaeschel) of the sponsoring organizations cooperate closely in the design and conduct of the project, but only the academic researchers have full access to all the data in this study and take complete responsibility for the integrity of the data and the accuracy of the data analysis.

\section{Description of authors' roles}

Simone Neubauer performed the statistical analyses and wrote the paper. Petra Menn was responsible for the multivariate regressions. Maria Grossfeld-Schmitz was responsible for the telephone interviews and assisted in writing the paper. Rolf Holle and Elmar Graesel supervised the study and assisted in writing the paper.

\section{Acknowledgments}

The IDA project ("Initiative Demenzversorgung in der Allgemeinmedizin") was initiated and financed by four partners with equal rights in the conception, development and implementation of the project: the Federal AOK (the largest statutory health insurance company in Germany), the Bavarian branch of AOK, and the research-based pharmaceutical companies Eisai and Pfizer. The aim of this public-private partnership is to improve the care of dementia patients and the support of their informal caregivers. This will give an impetus for further development of the public healthcare system. 


\section{References}

Belle, S. H. et al. (2006). Enhancing the quality of life of dementia caregivers from different ethnic or racial groups: a randomized, controlled trial. Annals of Internal Medicine, 145, 727-738.

Brouwer, W. B., van Exel, N. J., Koopmanschap, M. A. and Rutten, F. F. (1999). The valuation of informal care in economic appraisal. A consideration of individual choice and societal costs of time. International Fournal of Technology Assessment in Health Care, 15, 147160.

Brouwer, W. B., van Exel, N. J., Van Den Berg, B., Van Den Bos, G. A. and Koopmanschap, M. A. (2005). Process utility from providing informal care: the benefit of caring. Health Policy, 74, 85-99.

Brouwer, W. B., van Exel, N. J., van Gorp, B. and Redekop, W. K. (2006). The CarerQol instrument: a new instrument to measure care-related quality of life of informal caregivers for use in economic evaluations. Quality of Life Research, 15, 1005-1021.

Clipp, E. C. and Moore, M. J. (1995). Caregiver time use: an outcome measure in clinical trial research on Alzheimer's disease. Clinical Pharmacology and Therapeutics, 58, 228-236.

Davis, K. L. et al. (1997). The Caregiver Activity Survey (CAS): development and validation of a new measure for caregivers of persons with Alzheimer's disease. International fournal of Geriatric Psychiatry, 12, 978-988.

Droes, R. M., Breebaart, E., Meiland, F. J., Van Tilburg, W. and Mellenbergh, G. J. (2004). Effect of Meeting Centres Support Program on feelings of competence of family carers and delay of institutionalization of people with dementia. Aging and Mental Health, 8, 201-211.

Drummond, M., MJ, S., Torrance, G. W., O'Brien, B. and Stoddart, G. (2005). Methods for the Economic Evaluation of Health Care Programmes. Oxford: Oxford University Press.

Engels, D. et al. (2005). Möglichkeiten und Grenzen selbständiger Lebensführung in privaten Haushalten (MUG III) - Potential and Limitation of Independent Living in Private Households in Germany. Munich: Federal Ministry for Family Affairs, Senior Citizens, Women and Youth.

Ferri, C. P. et al. (2005). Global prevalence of dementia: a Delphi consensus study. The Lancet, 366, 2112-2117.

Gold, M., Siegel, J. E., Russell, L. B. and Weinstein, M. C. (1996). Cost-effectiveness in Health and Medicine. Oxford: Oxford University Press.

Jansen, A. P. et al. (2005). (Cost)-effectiveness of case-management by district nurses among primary informal caregivers of older adults with dementia symptoms and the older adults who receive informal care: design of a randomized controlled trial [ISCRTN83135728]. BMC Public Health, 5, 133.

Jonsson, L. et al. (2006). Determinants of costs of care for patients with Alzheimer's disease. International Fournal of Geriatric Psychiatry, 21, 449-459.

Lubke, N., Meinck, M. and von Renteln-Kruse, W. (2004). The Barthel Index in geriatrics. A context analysis for the Hamburg Classification Manual. Zeitschrift für Gerontologie und Geriatrie, 37, 316-326.

Mittelman, M. S. et al. (1993). An intervention that delays institutionalization of Alzheimer's disease patients: treatment of spouse-caregivers. The Gerontologist, 33, 730-740.

O'Shea, E. and O'Reilly, S. (2000). The economic and social cost of dementia in Ireland. International Fournal of Geriatric Psychiatry, 15, 208-218.

Smithson, M. and Verkuilen, J. (2006). A better lemon squeezer? Maximum-likelihood regression with beta-distributed dependent variables. Psychological Methods, 11, 54-71.

van den Berg, B. and Spauwen, P. (2006). Measurement of informal care: an empirical study into valid measurement of time spent on informal caregiving. Health Economics, 15, 447-460. 
van den Berg, B., Brouwer, W. B. and Koopmanschap, M. A. (2004). Economic valuation of informal care. An overview of methods and applications. European fournal of Health Economics, 5, 36-45.

van den Berg, B., A1, M., Brouwer, W., van Exel, J. and Koopmanschap, M. (2005a). Economic valuation of informal care: the conjoint measurement method applied to informal caregiving. Social Science and Medicine, 61, 1342-1355.

van den Berg, B., Brouwer, W., van Exel, J. and Koopmanschap, M. (2005b). Economic valuation of informal care: the contingent valuation method applied to informal caregiving. Health Economics, 14, 169-183.

van den Berg, B., Brouwer, W., van Exel, J., Koopmanschap, M., van den Bos, G. A. and Rutten, F. (2005c). Economic valuation of informal care: Lessons from the application of the opportunity costs and proxy good methods. Social Science $\mathcal{E}$ Medicine.

Wahle, M., Haller, S. and Spiegel, R. (1996). Validation of the NOSGER (Nurses' Observation Scale for Geriatric Patients): reliability and validity of a caregiver rating instrument. International Psychogeriatrics, 8, 525-547.

Wimo, A. and Nordberg, G. (2007). Validity and reliability of assessments of time. Comparisons of direct observations and estimates of time by the use of the resource utilization in dementia (RUD)-instrument. Archives of Gerontology and Geriatrics, 44, 71-81.

Wimo, A., Wetterholm, A. L., Mastey, V. and Winblad, B. (1998). Evaluation of the healthcare resource and caregiver time in anti-dementia drug trials: a quantitative battery. In A. Wimo, B. Jönsson, G. Karlsson and B. Winblad (eds.), Health Economics of Dementia (pp. 465-499) Chichester: John Wiley \& Sons Ltd.

Wimo, A., Nordberg, G., Jansson, W. and Grafstrom, M. (2000). Assessment of informal services to demented people with the RUD instrument. International fournal of Geriatric Psychiatry, 15, 969-971.

Wimo, A., Jonsson, L. and Winblad, B. (2006). An estimate of the worldwide prevalence and direct costs of dementia in 2003. Dementia and Geriatric Cognitive Disorders, 21, 175-181. 